\title{
REVIEW
}

\section{Surgery for Peyronie's disease}

\author{
Laurence A Levine and Stephen M Larsen
}

Peyronie's disease (PD) is most simply referred to as a fibrotic wound-healing disorder of the tunica albuginea. It is both a physically and psychologically devastating disorder that causes penile deformity, curvature, hinging, narrowing and shortening, which may compromise sexual function. Although a variety of non-surgical treatments have been suggested, none to date offer a reliable and effective correction of the penile deformity. As a result, surgery remains the gold standard treatment option, offering the most rapid and reliable treatment which will be the focus of this article. We review the preoperative evaluation, surgical algorithm, graft materials and postoperative management of PD. Outcomes for tunical shortening, tunical lengthening and penile prosthesis placement for penile straightening are reviewed. Tunica albuginea plication is the preferred method of straightening for men with adequate rigidity and less severe disease defined as curvature less than $70^{\circ}$ without narrowing/hinging. Men who have more severe, complex deformity, but maintain strong preoperative erectile function should be considered candidates for straightening with plaque incision or partial excision and grafting. Finally, for those men who have inadequate rigidity and PD, penile prosthesis placement with straightening is the best approach to address both problems. Asian Journal of Andrology (2013) 15, 27-34; doi:10.1038/aja.2012.92; published online 26 November 2012

Keywords: penile prosthesis; Peyronie's disease, penile reconstruction; plaque excision and grafting; plaque incision; tunica albuginea plication

\section{INTRODUCTION}

Peyronie's disease (PD) is most simply referred to as a fibrotic woundhealing disorder of the tunica albuginea. It is both a physically and psychologically devastating disorder that causes penile deformity, curvature, hinging, narrowing, shortening and painful erections. ${ }^{1}$ The perceived loss of length and girth is often more disturbing than the curvature itself, all of which can lead to moderate to severe depressive symptoms, emotional, and relationship problems. ${ }^{2,3}$ Despite a myriad of treatment options, PD remains a considerable therapeutic dilemma due to several factors including an incomplete understanding of its etiopathophysiology and the relative paucity of randomized, placebo-controlled trials. A general explanation of this disorder, which has gained acceptance, is that PD is a disorder in which genetically susceptible individuals experience a localized response to endogenous factors such as tumor growth factor- $\beta$, which are released in response to microtrauma. This can lead to biological transformation of cells within the tunica albuginea, cell cycle dysregulation, genotypic changes and increased expression of cytokines and free radicals. This inflammatory response leads to unregulated extracellular matrix deposition including fibronectin and collagen, and ultimately plaque scar formation, which does not appear to undergo proper scar remodeling, leaving an inelastic segment in the involved tunica albuginea. ${ }^{4-9}$

Although a variety of non-surgical treatments have been suggested, none offer a reliable and effective correction of the penile deformity. ${ }^{10}$ As a result, surgery remains the gold standard treatment option, offering the most rapid and reliable treatment which will be the focus of this article.

\section{PREOPERATIVE EVALUATION}

The preoperative evaluation of $\mathrm{PD}$ is critical for differentiating simple from complex disease, which will in turn dictate what type of surgical approach will be most beneficial to the patient. Levine and Greenfield ${ }^{11}$ suggested a standardized evaluation addressing history, physical examination, diagnostic imaging and non-validated questionnaires. The history should specifically address time of onset, pain, deformity, palpable lump, any trauma that may have preceded the onset of symptoms by days to months, and any previous treatments the patient may have undergone. It is useful to ask the patient to estimate the degree and direction of erect penile curvature. However, it has been demonstrated that only $20 \%$ of patients accurately report the degree of curvature with $56 \%$ overestimating and $26 \%$ underestimating curvature with an average difference of $20^{\circ}$, which is why preoperative objective measures of erect deformity are necessary in order to accurately counsel patients, recommend appropriate treatment and objectively evaluate outcomes. ${ }^{12}$ The history should also address the presence of indentation, hinging/buckling with axial forces and amount of shortening. Although curvature is the hallmark symptom of disease, shortening can be the most psychologically devastating, occurring in $70 \%$ of patients and ranging from 1 to $10 \mathrm{~cm} .^{2,3}$ Determining whether there is a family history of PD or other fibrotic disorders such as Dupuytren's is also useful as it does appear to occur more frequently among males in the same family and through generations.

Questions regarding pre-Peyronie's erectile status are important and guide surgical planning. Although diminished rigidity may be associated with several underlying medical conditions such as diabetes, smoking and peripheral vascular disease, it may also be psychogenic in nature given the devastating psychological effects that PD has on the affected individual. ${ }^{2,13}$ Questions regarding sexual dysfunction should include ejaculation, orgasm, and change in sensation.

Physical examination of the penis is clearly critical. A stretched penile length must be obtained because of the concern for further

Department of Urology, Rush University Medical Center, Chicago, IL 60612, USA 
shortening that may occur with this scarring disorder and/or as a result of surgery. The technique described by Wessells et al. ${ }^{14}$ is recommended. With the patient in the supine position, the glans is grasped and pulled to full stretch at $90^{\circ}$ from the plane of the body. ${ }^{14}$ A rigid ruler is used by pressing down on the suprapubic fat pad to the pubic bone, and the penis is measured dorsally to the corona or meatus depending on physician preference.

Preoperative penile sensitivity can be assessed with light touch and biothesiometry, though no standard evaluation of this parameter has been established. Biothesiometry has been suggested to be an indirect measure of penile sexual sensation, as vibratory nerves travel with penile sexual sensory nerves. Intact vibratory sensation should correlate with sexual sensation.

The most important part of the clinical diagnosis and preoperative evaluation is to visually evaluate the penis in the erect state so that objective measures can be made of the deformity. Pharmacologically induced erection via injection of vasoactive agent such as papaverine alone, Tri-Mix (papaverine, phentolamine and prostaglandin E1), or prostaglandin alone is the most reliable method when compared to vacuum induced or photograph of office or home erection. ${ }^{15}$ This is also useful as it is an indicator of vascular integrity and erectile response to the injected vasoactive drug. If a full erection does not occur, redosing is recommended to try to obtain an erection which is equal to or better than that which can be obtained at home with sexual stimulation. Pressure can also be applied to the base of the penis if needed as psychogenic inhibition during direct observation can be significant. Curvature is then measured in the erect state with a goniometer or protractor, while a simple string can be used to measure girth at the base, subcoronal area and any area of indentation/hourglass narrowing. Duplex ultrasound can also be incorporated in the flaccid condition looking for corporal fibrosis and plaque calcification. ${ }^{16,17}$ Recent reports have suggested that up to $30 \%$ of men with PD will have plaque calcification, and contrary to previous reports, this can occur early after initial onset of the plaque formation and therefore, may not be an indicator of mature disease. ${ }^{18}$ This same study found when using a new Plaque Calcification grading system that $50 \%$ of men with extensive calcification underwent surgery of which $77 \%$ had plaque incision with grafting.

Indications for surgical reconstruction for men with PD include: (i) stable disease, defined as at least 1 year from onset and at least 6 months of stable deformity; (ii) compromised ability to engage in coital activity due to deformity and/or inadequate rigidity; (iii) failure of conservative therapy; (iv) extensive plaque calcification; and (v) patient desires most rapid and reliable correction once disease is stable. Penile pain is a relative contraindication except when it may be due to a strong erection imparting torque-like pressure on the penis. ${ }^{19}$

Obtaining preoperative consent is a critical aspect of PD management mainly because most patients with PD are distressed and emotionally devastated. It is important to have a frank discussion so that he understands the possible limitations of the operation, and set appropriate expectations regarding outcomes to optimize patient

Set expectations regarding outcome
- Persistent/Recurrent curvature
-Goal, "Functionally straight" $<20^{\circ}$
- Change in length
- More likely shorter with plication vs. grafting
- Diminished rigidity
$-\geq 5 \%$ in all studies, especially with grafting
-Dependent upon pre-op erectile quality
- Decreased sexual sensation
-Common but infrequently reported to compromise orgasm/ejaculation

Box 1 Preoperative surgical consent issues.

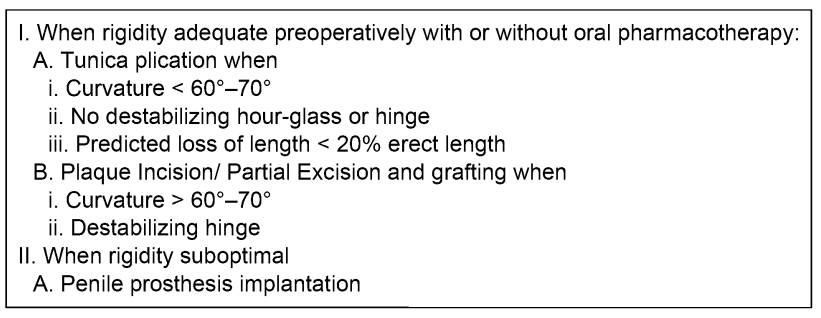

Box 2 Peyronie's disease surgical algorithm.

satisfaction. ${ }^{19,20}$ One must address the possibility of persistent or recurrent curvature, change in penile erect length, diminished rigidity and decreased sexual sensation (Box 1).

Persistent or recurrent curvature is unusual, but has been shown in up to $16 \%$ of men. ${ }^{19,21}$ The patient should understand that the goal is to make him 'functionally straight', which expert opinion defines as a residual deformity of $20^{\circ}$ or less. Change in penile erect length is more likely in plication $v s$. grafting though all surgical correction procedures have been associated with some length loss. This is extremely important for the patient to understand preoperatively as $70 \%-80 \%$ of PD patients initially present with loss of length due to the fibrotic disease process. ${ }^{19,20}$ Erectile rigidity will not likely be made better by the procedure, and therefore, consideration for penile prosthesis should be discussed if the patient already has significant erectile dysfunction (ED) preoperatively. ${ }^{19,21}$ Decreased sexual sensation has been examined and reported upon infrequently, but it does appear that around $20 \%$ of men will describe some reduction in penile sensitivity, rarely interfering with orgasm or ejaculation. Sensory change whether it is hypesthesia or hypoesthesia may occur in the acute postoperative period but tends to resolve over the ensuing months. ${ }^{22}$

\section{SURGICAL ALGORITHM FOR THE MANAGEMENT OF PD}

Several surgical algorithms have been published and are summarized in Box 2. ${ }^{23-25}$

In men who have rigidity which is adequate for coital activity with or without pharmacotherapy, tunica plication techniques $v s$. plaque incision or partial excision and grafting (PEG) techniques may be employed. Tunica plication techniques are recommended for those who have a simple curve of less than $60-70^{\circ}$, absence of hourglass or hinge effect, and when the anticipated loss of length would be less than $20 \%$ of the total erect or stretched length. Plaque incision or partial excision and grafting is recommended for those men with more complex curves of greater than $60-70^{\circ}$ and/or have a destabilizing hourglass or hinge effect. These men should have strong sexually induced rigidity to reduce the likelihood of postoperative ED. ${ }^{26,27}$ (Box 3).

In the man with $\mathrm{PD}$ who also has $\mathrm{ED}$ that does not respond to medical therapy, published surgical algorithms have indicated that penile prosthesis placement is the procedure of choice. ${ }^{23,25,28}$ This allows for correcting the deformity while addressing the ED as well. If curvature is not satisfactorily corrected after the prosthesis is inflated at the time of placement, additional straightening maneuvers may be performed. The recommended first step is manual modeling, as

- No significant loss of erectile capacity
- Curvature $>60^{\circ}-70^{\circ}$
- Severe indentation causing unstable erection (hinge effect)
- Extensive calcification
- Understands increased risk of postoperative erectile dysfunction

Box 3 Indications for surgical correction with grafting. 
initially reported by Wilson and Delk. ${ }^{29}$ If after modeling, there is residual curvature in excess of $30^{\circ}$, then an incision in the tunica albuginea overlying the area of maximum curvature can be made. It is recommended that if the incisional defect is greater than $2 \mathrm{~cm}$ in any dimension, then a biograft should be placed over the defect to prevent cicatrix contracture of the incision or herniation of the prosthesis (Box 4). ${ }^{28}$

\section{TUNICAL SHORTENING PROCEDURES}

Multiple surgical plication techniques have been offered for PD, beginning with the Nesbit procedure, which is a form of excision of tunica on the contralateral side of the curvature. ${ }^{30}$ In the setting of a ventral curvature, once Buck's fascia has been elevated, small wedges of the contralateral dorsal tunica albuginea are excised and then the defect is closed, typically with permanent suture. Variations on this approach have evolved, including the Yachia procedure, which utilizes the Heineke-Mikulicz technique. ${ }^{31}$ In the setting of a dorsal curvature, a short full-thickness vertical incision is made on the ventral shaft tunic opposite the area of maximum curvature, which is then closed transversely to shorten the ventral aspect and correct the curvature.

The 16-dot procedure has also been presented where there is no incision, but the tunica albuginea is plicated with permanent suture using an extended Lembert-type suture technique. ${ }^{32,33}$ Another variation is the Levine modification of the Duckett-Baskin tunica albuginea plication (TAP) which was originally used for children with chordee and has been modified for PD. A partial thickness incision is made transversely on the contralateral side to the point of maximum curvature. ${ }^{34,35}$ A pair of transverse parallel incisions are made from 1 to $1.5 \mathrm{~cm}$ in length down through the longitudinal fibers, but do not violate the inner circular fibers of the tunic. These incisions are separated by $0.5-1.0 \mathrm{~cm}$ and the longitudinal fibers between the two transverse incisions are removed so as to reduce the bulk of the plication. This procedure can be done with a combination of permanent and absorbable sutures.

The key is that all plication procedures shorten the long side of the penis and therefore can result in loss of length on that aspect. Studies have examined the loss of penile length using the TAP technique where the factors which predicted loss of length were the direction of curvature and degree of curvature. ${ }^{36}$ Therefore, those men who have a ventral curvature of greater than $60^{\circ}$ tend to have the greatest potential loss of penile length.

The drawbacks of any tunica plication procedure for PD are that it does not correct shortening and potentially may enhance loss of penile shaft length. It does not address hinge or hourglass effect and may exacerbate it, resulting in an unstable penis. Penile narrowing or induration has been reported in $0 \%-17 \%$. In addition, there can be pain associated with the knots, suture granulomas and, as noted, a potential for tactile and sexual sensitivity changes in $0 \%-21 \%{ }^{19,22,37}$ Surgical straightening with a variety of plication procedures can be expected in $85 \%-100 \%$ of patients with a satisfaction rate of $67 \%-100 \%$. Recurrence of penile curvature deformity $\left(>30^{\circ}\right)$ has been reported at a rate of $8 \%-11 \%$, the reported risk of new ED ranges from $0 \%$ to $23 \%$ and diminished sensation is reported in $4 \%$ $21 \%$, with follow-up of up to 89 months. Lastly, hematoma can be seen in $0 \%-9 \%$, urethral injury in $0 \%-1.4 \%$ and phimosis in $0 \%-5 \%{ }^{37}$

The International Consultation of Sexual Medicine published their recommendations regarding plication procedures, and reported that

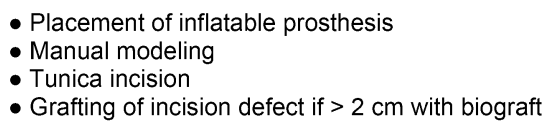

Box 4 Algorithm for prosthesis placement. there was 'no evidence that one surgical approach provides better outcomes over another, but curvature correction can be expected with less risk of new ED' compared to grafting procedures. ${ }^{19}$ See Table 1 for a summary on the outcomes for tunical shortening procedures.

\section{TUNICAL LENGTHENING PROCEDURES (INCISION OR PARTIAL EXCISION AND GRAFTING)}

Indications for incision or PEG for surgical correction of PD include greater complexity of disease with several or all of the following: curvature greater than $60^{\circ}-70^{\circ}$, shaft narrowing, hinging and extensive plaque calcification. Most importantly, for a patient to be a candidate for incision or partial excision and grafting, they must have good preoperative erections. ${ }^{26}$ This can be determined during the patient interview, where he is asked directly: 'if your penis was straight, would the quality of rigidity that you currently have allow intercourse?'. Should the patient hesitate, the incision and grafting procedure should not be performed, unless they fully understand the risk of more advanced postoperative ED and the possible need for subsequent prosthesis placement to attain adequate rigidity.

Other factors have emerged in the literature as possible predictors of postoperative $\mathrm{ED}$, including age $>55$ years, evidence of corporal venoocclusive dysfunction on duplex ultrasound analysis, with a resistance index of less than 0.80 , ventral curvature, and possibly the severity of the curvature..$^{27,38,39}$ These predictors have been suggested as a result of single-center studies with a limited number of patients in each cohort. Larger scale studies indicate that the most critical criterion for any grafting procedure appears to be the quality of their preoperative erections. ${ }^{26,27,39}$

Surgical grafting techniques include plaque incision or partial plaque excision. Historically, total excision of the plaque was practiced to 'cut out the disease', resulting in onlays of large grafts with an unacceptably high rate of ED. ${ }^{40}$ Therefore, plaque incision was introduced, where a modified $\mathrm{H}$ or double-Y incision is made in the area of maximum curvature. ${ }^{41}$ This allows the tunic to be expanded in this area, thereby correcting the curvature and shaft caliber. Occasionally, multiple incisions with grafting are needed to obtain satisfactory straightening, or plication may be used for optimal correction of deformity.

Partial plaque excision has also been suggested, where the area of maximum deformity is excised particularly if it is associated with severe indentation. The corners of the defect are darted in a radial fashion to enhance correction of narrowing in that area. ${ }^{42}$ Geometrical principles have been applied to the grafting technique in an effort to obtain a reliably sized graft, this approach appears unnecessarily complex and there have been reports of a higher rate of ED when this technique is used. ${ }^{27,43}$ Egydio et al. ${ }^{44}$ reported the results of the incomplete circumferential incision of a penile plaque and the use of a bovine pericardial graft. The authors achieved an $88 \%$ rate of penile correction in $33 \mathrm{PD}$ patients, with a mean increase of $2.21 \mathrm{~cm}$ in penile length. ${ }^{44}$ Alternatively, Kargi et al. ${ }^{45}$ reported on a relaxing incision and fascia lata grafting for the surgical correction of penile curvature in men with PD. Autologous fascia lata grafts were harvested from the lateral thigh in 12 patients with preoperative curvature measuring $30^{\circ}-40^{\circ}$. No ED or penile angulation was observed after one or more years of follow-up, and all had statistically significant penile lengthening. ${ }^{45}$ Regardless, it is recommended that the defect should be expanded so as to allow correction of curvature and indentation. The key to these operations is to limit the trauma to the underlying cavernosal tissue to maintain the veno-occlusive relationship between the cavernosal tissue and the overlying tunic and graft.

Penile straightening after an incision/excision procedure plus grafting was achieved in $63 \%-100 \%{ }^{46-48}$ The reported patient satisfaction 
Table 1 Outcome of tunical shortening procedures for Peyronie's disease

\begin{tabular}{|c|c|c|c|c|c|c|}
\hline Procedure type & Reference number & Number of patients & $\begin{array}{l}\text { Mean follow-up } \\
\text { duration (months) }\end{array}$ & $\begin{array}{l}\text { Straight at latest } \\
\text { follow-up (\%) }\end{array}$ & $\begin{array}{l}\text { Erectile dysfunction } \\
\text { (\%) }\end{array}$ & $\begin{array}{l}\text { Satisfaction } \\
\text { rates (\%) }\end{array}$ \\
\hline \multirow{5}{*}{ Nesbit } & 104 & 218 & 89 & 86 & 12 & 84 \\
\hline & 105 & 40 & 81 & 88 & 5 & NA \\
\hline & 107 & 359 & 21 & 82 & 2 & NA \\
\hline & 108 & 28 & 22 & 79 & 4 & 79 \\
\hline & 109 & 9 & 31 & NA & NA & 67 \\
\hline \multirow{2}{*}{ Yachia } & 111 & 26 & 22 & 73 & 8 & 78 \\
\hline & 109 & 8 & 31 & NA & NA & 63 \\
\hline \multirow[t]{7}{*}{ Tunica albuginea plication } & 32 & 124 & 31 & 85 & 6 & 96 \\
\hline & 112 & 44 & 49 & 29 & 36 & NA \\
\hline & 113 & 28 & 34 & 57 & 3.5 & 82 \\
\hline & 114 & 29 & 34 & 79 & 38 & $81^{\mathrm{a}}, 62^{\mathrm{b}}$ \\
\hline & 99 & 26 & $\geqslant 12$ & 65 & 11 & 65 \\
\hline & 118 & 76 & 71 & 42 & 60 & NA \\
\hline & 119 & 15 & 21 & 87 & NA & 93 \\
\hline
\end{tabular}

Abbreviation: NA, not available.

a Percent satisfied with cosmetic result.

${ }^{b}$ Percent satisfied with functional results; Mean postoperative curvature of $15^{\circ}\left(0^{\circ}-25^{\circ}\right)$.

rate with these procedures ranges from $41 \%$ to $96 \%$, partner satisfaction has been reported at $77 \%$ and rigidity adequate for coitus reported from $79 \%$ to $100 \% .^{22,46,48-51} \mathrm{ED}$ is reported in $0 \%-35 \%$ with a trend toward increased risk of ED in men over the age of 60 years, as well as a higher risk of ED when grafting is performed to correct ventral curvature. $^{22,48}$ Depending on the graft material used, recurrence of greater than $30^{\circ}$ curvature can be seen from $0 \%$ to $16 \%$ with plaque incision/excision and grafting procedures. ${ }^{48,51}$

\section{Graft materials}

The concept of the ideal graft has been debated. At this time, no graft has been identified as the ultimate one. Multiple grafts have been used historically, including fat, dermis, tunica vaginalis, duramater, temporalis fascia, saphenous vein, crura and buccal mucosa, which are harvested from the patient. ${ }^{52-59}$ These have fallen out of favor because of a need for extended surgery to harvest the graft as well as a second surgical site, which possesses its own potential complications of healing, scarring and possible lymphedema. Synthetic polyethylene terephthalate (Dacron) and polytetrafluoroethylene (Teflon) grafts have been used historically and are not recommended now as there is a potential risk of infection, localized inflammatory response and fibrosis. ${ }^{60}$ Finally, 'off-the-shelf allografts and xenografts have emerged, including processed pericardium from a bovine or human source, porcine intestinal submucosa and porcine skin. The two most common grafts currently used are Tutoplast (Coloplast US, Minneapolis, MN, USA) processed human and bovine pericardium, and small intestinal submucosa (SIS) grafts (Surgisis ES, Cook Urological, Spencer, IN, USA). ${ }^{61,62}$ The pericardial grafts are thin, strong, do not contract and have virtually absent reported infection or rejection rate. Chun et al. ${ }^{63}$ performed a comparison of dermal and nontutoplast processed human cadaveric pericardial grafts in the modified Horton-Devine procedure. Overall, $92 \%$ were able to achieve successful coitus with or without assistance. They reported a $33 \%$ overall recurrence rate with $26 \%$ of patients receiving dermal grafts and $44 \%$ of patients receiving pericardial grafts experiencing recurrence. However, this study did not report on the severity of recurrence, and all of these patients were able to achieve erections suitable for coitus. Satisfaction rates were similar and those who underwent pericardial grafting enjoyed shorter operative times as well as decreased morbidity associated with the absence of a graft donor site. ${ }^{63}$ The SIS grafts have similar advantages to pericardium, except that there have been reports of graft contraction of up to $25 \%$ with associated recurrent curvature in the $37 \%-75 \%$ range. $22,47,64-67$ Other reported postoperative complications with SIS grafts include hematoma at $26 \%$ as well as an infection rate of $5 \%{ }^{47}$

Tissue engineered graft materials such as adipose tissue-derived stem cell seeded SIS, human acellular matrix tunica albuginea grafts, and autologous tissue engineered endothelialized tunica albuginea grafts are being investigated for incision/excision procedures. ${ }^{68-71}$ Imbeault et al. ${ }^{71}$ demonstrated in vitro creation of artificial tunica albuginea using human dermal fibroblasts and human endothelial cells. They concluded that this tissue-engineered endothelialized tubular graft was structurally similar to normal tunic with a high burst pressure and adequate mechanical resistance. Furthermore, the autologous property of this model could represent an advantage comparatively to other available grafts. ${ }^{71}$ Such studies may help elucidate future surgical treatments for PD using tissue engineered grafts for reconstruction of the tunica albuginea. The biomechanical properties, compatibility with tunica albuginea, and the effective neovascularization of the tissue engineered grafts need to be investigated further before such basic research can be applied by the reconstructive urologist.

\section{Postoperative management}

The postoperative rehabilitation period is critical to reduce the risk of postoperative ED and length loss as well as optimize straight healing. Typically a patient is seen 2 weeks after surgery, at which point, massage and stretch therapy is initiated. ${ }^{72,73}$ The patient is instructed to grasp the penis by the glans and gently stretch it and then with his other hand massage the shaft of the penis for 5 min twice per day for 2-4 weeks. The massage and stretch can be performed by the patient's 
partner for the second 2 weeks if possible. This will reinitiate the sexual experience for the couple and hopefully diminish the fear of reinjuring the penis, for which the partner may feel responsible. Investigators have recommended the use of nocturnal PDE5 inhibitors to enhance postoperative vasodilation, which may help support graft take as well as reduce cicatrix contraction. ${ }^{57}$ Finally, external penile traction devices have been encouraged and have been recently shown to reduce length loss postoperatively and can even enhance the likelihood of further length gain with both grafting and plication procedures. In a recent study accepted for publication, stretched penile length in patients who used postoperative traction therapy was shown to increase after TAP and PEG procedures by +0.85 and $+1.48 \mathrm{~cm}$ respectively versus changes of -0.53 and $+0.24 \mathrm{~cm}$ in the TAP and PEG groups who did not use postoperative traction. In fact, $50 \%$ of the TAP and $89 \%$ of the PEG patients using postoperative traction had measured length gain. The reported average daily use was $2.5 \mathrm{~h}$, for 4.5 days a week, for an average duration of 3.8 months. There was no patient-perceived postoperative length loss among those who used postoperative traction therapy, and although not statistically significant, there was a trend of higher satisfaction for erect length in the groups who used postoperative traction. ${ }^{74}$
In a review of the published reports on grafting for PD over the past 12 years, satisfactory straightening was found in $74 \%-100 \%$ of patients, but postoperative ED, which does not have a uniform definition in the literature, has been reported in $5 \%-53 \%$ of patients. Diminished sensation after grafting has been reported in a few series with a follow-up of less than 5 years. ${ }^{21}$ In the few single-center surgical outcome reviews with 5 or more years of follow-up, ED has been reported in up $24 \%$, with recurrent or persistent curvature in the $8 \%-12 \%$ range $^{50,66,75}$ See Table 2 for a summary of the outcomes for penile straightening with plaque incision/excision and grafting.

\section{PENILE PROSTHESIS FOR MEN WITH PD}

\section{Indications}

As described above, in men with PD and concurrent ED refractory to PDE5 inhibitors, penile prosthesis placement is the procedure of choice. $^{23-25,28}$ Manual modeling may then be performed if necessary as only patients with mild curvature or presence of hinging without curvature will be fully corrected with prosthesis placement alone. Incising the tunica albuginea is then indicated if residual curvature is in excess of $30^{\circ}$ after modeling attempts. Grafting of this incisional

Table 2 Outcomes for plaque excision/incision and grafting

\begin{tabular}{|c|c|c|c|c|c|c|}
\hline Graft material & $\begin{array}{c}\text { Reference } \\
\text { number }\end{array}$ & $\begin{array}{c}\text { Number of } \\
\text { patients }\end{array}$ & $\begin{array}{l}\text { Mean follow-up } \\
\text { duration (months) }\end{array}$ & $\begin{array}{c}\text { Straight at latest } \\
\text { follow-up (\%) }\end{array}$ & $\begin{array}{c}\text { Erectile } \\
\text { dysfunction (\%) }\end{array}$ & $\begin{array}{l}\text { Satisfaction rates } \\
(\%)\end{array}$ \\
\hline \multirow[t]{4}{*}{ Dermal grafts } & 63 & 10 & 11 & 60 & 6 & 70 \\
\hline & 65 & 15 & 17 & 73 & 12 & 70 \\
\hline & 87 & 48 & 19.6 & 80 & 25 & 73 \\
\hline & 88 & 50 & 45 & 94 & NA & NA \\
\hline \multirow[t]{6}{*}{ Saphenous vein grafts } & 50 & 113 & 12 & 86 & 15 & 96 \\
\hline & 86 & 112 & $\leqslant 18$ & 96 & 12 & 92 \\
\hline & 96 & 51 & 16 & 82 & 8 & 92 \\
\hline & 97 & 50 & 32 & 80 & 6 & 88 \\
\hline & 98 & 50 & $>60$ & 72 & 22 & 60 \\
\hline & 99 & 20 & $>12$ & 85 & 35 & NA \\
\hline \multirow[t]{2}{*}{ Buccal mucosa } & 48 & 15 & 12 & 100 & 0 & 100 \\
\hline & 59 & 26 & 38.4 & 92.3 & 7.7 & NA \\
\hline \multirow[t]{3}{*}{ Proximal crura } & 58 & 7 & 6 & 85.7 & 0 & 85.7 \\
\hline & 91 & 31 & NA & 83.8 & 19.3 & 93.5 \\
\hline & 92 & 27 & NA & 96.2 & 3.7 & 70.4 \\
\hline \multirow[t]{2}{*}{ Tunica vaginalis } & 55 & 15 & $4-16$ & 87.5 & 0 & 100 \\
\hline & 89 & 25 & 42.2 & 88 & 68 & NA \\
\hline \multirow[t]{2}{*}{ Dura mater } & 56 & 40 & $12-72$ & 95 & 15 & NA \\
\hline & 93 & 40 & $12-24$ & 100 & 25 & NA \\
\hline Temporalis fascia & 90 & 12 & NA & 100 & 0 & 100 \\
\hline \multirow[t]{2}{*}{ Fascia lata } & 45 & 12 & 10 & 100 & 0 & 100 \\
\hline & 100 & 14 & 31 & 79 & 7 & 93 \\
\hline \multirow[t]{2}{*}{ Pericardial graft } & 44 & 33 & 19 & 87.9 & 0 & NA \\
\hline & 63 & 9 & 6 & 55 & 11 & 88 \\
\hline Stratasis grafts & 65 & 13 & 7.8 & 76.9 & NA & 84.6 \\
\hline \multirow[t]{4}{*}{ Small intestinal submucosa (SIS) } & 47 & 19 & 15 & 63 & 53 & NA \\
\hline & 62 & 162 & 38 & 91 & 9 & NA \\
\hline & 94 & 33 & 14 & 67 & 11 & 79 \\
\hline & 95 & 13 & NA & 100 & 54 & NA \\
\hline Tutoplast & 22 & 81 & 58 & 79 & 20 & 78 \\
\hline \multirow[t]{5}{*}{ Pericardial graft } & 51 & 19 & 22 & 84 & 16 & 74 \\
\hline & 61 & 11 & 14 & 91 & NA & NA \\
\hline & 65 & 11 & 19 & 91 & 0 & NA \\
\hline & 85 & 13 & 30 & 100 & NA & NA \\
\hline & 101 & 40 & 22 & 98 & 30 & 92 \\
\hline Acellular dermis & 102 & 5 & 6 & 100 & 0 & 100 \\
\hline Syntnetic Materials & 103 & 9 & 17.5 & 100 & 0 & 100 \\
\hline
\end{tabular}

Abbreviation: NA, not available. 
defect is recommended if it is greater than $2 \mathrm{~cm}$ in any dimension to reduce cicatrix contracture and cylinder herniation.

Techniques for straightening when placing penile prosthesis for PD An inflatable penile prosthesis appears to be the preferred surgical implant, as the pressure within the cylinders allows for superior correction of curvature with manual modeling, as well as improved girth enhancement. Malleable prostheses when used for PD historically, were associated with narrow, cold and less than natural erections. ${ }^{76}$

Manual modeling via the penoscrotal approach is recommended with a high-pressure inflatable cylinder, but all available three-piece and two-piece devices have been used successfully to correct deformity. Our approach is to place the prosthesis cylinders first, and then the corporotomies are closed. Using a surrogate reservoir attached to the pump tubing, the prosthesis can be filled to full rigidity, which will allow visualization of the deformity. To protect the pump from the high pressures that may occur during manual modeling, shodded hemostat clamps can be applied to the tubing between the pump and the cylinders. The penis is then bent in the contralateral direction to the curvature. It is recommended to try to hold the penis in this position for 60-90 s, but experience has suggested that around $30 \mathrm{~s}$ may be all that is possible. Regardless, once the modeling is performed, the penis can be reassessed by inflating more fluid, reapplying the hemostats, and then performing the modeling procedure repeatedly until satisfactory curvature correction is attained. The modeling technique should be a gradual bending rather than a violent maneuver, as this will reduce the likelihood of inadvertent tearing of the tunic or injury to the overlying neurovascular bundle. Urethral injuries while performing this technique by distal extrusion of the prosthetic cylinders at the fossa navicularis has been reported by Wilson et al. ${ }^{29,77}$ To reduce the likelihood of this occurring, the bending hand should be placed on the shaft of the penis rather than the glans, to avoid downward pressure on the tips of the cylinders. The other hand should be grasping the base of the penis with pressure over the corporotomies, which will provide support to this area and reduce the likelihood of disruption of the suture line.

Published reports on the use of modeling have indicated that sensory deficits after manual modeling are rare, but are a potential complication that should be discussed with the patient preoperatively. ${ }^{78}$ Although it would appear that for more severe curvature that more advanced techniques will be necessary, published experience has suggested that manual modeling may be used as first-line therapy for correction of curvature after prosthesis implantation. An alternative to this would be to perform a tunic plication such as the 16-dot suture technique contralateral to the curvature before placement of the prosthesis so as to correct curvature. ${ }^{79}$

When there is residual curve of greater than $30^{\circ}$ or residual indentation causing the inflated cylinder to buckle, tunical incision is recommended after elevating Buck's fascia in that area. The transverse penoscrotal skin incision will allow access to virtually the entire shaft, except when the curvature is distal on the shaft, so degloving the penis is not always necessary. The tunical incision is made with the cylinders deflated, using the cautery to release the tunic with an effort to preserve the cavernosal tissue over the implant. When Coloplast (Coloplast) cylinders are used, the energy should be less than $30 \mathrm{~W}$ to reduce potential cylinder injury. ${ }^{80}$ Once the incision is made, the cylinders are re-inflated and further modeling can be performed to optimize deformity correction.

Although there is not a clearly accepted approach, grafting over the defect is recommended when the defect measures greater than $2 \mathrm{~cm}$ in any dimension.

Historically, synthetic grafts were used, but currently biografts of pericardium or porcine SIS are recommended. Use of locally harvested dermal grafts is not recommended, as there is risk of transferring bacteria to the prosthesis.

There have been limited publications looking at the long-term results with regard to outcomes and satisfaction with inflatable penile prostheses in men with PD and ED refractory to PDE5 inhibitors. Recently Levine et al. ${ }^{78}$ reported on 90 consecutive men undergoing placement of an inflatable penile prosthesis, with $4 \%$ having satisfactory straightening with prosthesis placement alone, $79 \%$ having satisfactory curvature correction with prosthesis and modeling, $4 \%$ required tunical incision and $12 \%$ had incision and pericardial grafting for correction of curvature. It did not appear that the additional maneuvers increased the rate of mechanical failure or infection. In the non-validated questionnaire used in this study, overall patient satisfaction was $84 \%$, whereas only $73 \%$ were satisfied with curvature correction. This may indicate a flaw in the design of the questionnaire, but may also reflect the general disappointment and frustration of patients with PD. ${ }^{78}$ Thus, preoperative counseling and setting appropriate expectations as with any prosthesis placement is critical. ${ }^{81}$

It is recommended that preoperative discussion is also focused on the goal of obtaining 'functional straightness', in which a residual curvature of $20^{\circ}$ or less in any direction would likely not compromise sexual activity.

By far, the most common postoperative complaint heard in men who undergo penile prosthesis placement is length loss. ${ }^{82}$ The first to objectively evaluate penile length after penile implant was Wang et al. ${ }^{83}$ who demonstrated decreases of $0.8,0.75$ and $0.74 \mathrm{~cm}$ at 6 weeks, 6 months and 1 year, respectively. This is of particular concern in the PD population in whom the majority report length loss at initial presentation. Any additional length loss due to the implant may be distressing to the patient and should be addressed preoperatively. For those men who cannot tolerate any further length loss, a recent small pilot study using traction therapy before penile prosthesis placement in men with $\mathrm{PD}$ as well as other disorders causing penile shortening (e.g. prosthesis explants, radical prostatectomy) did demonstrate that, after 3-4 months of daily traction for an average of $3 \mathrm{~h}$ or more per day, there was no further loss of length after prosthesis placement, and the majority had gained some length $(0.5-2.0 \mathrm{~cm})$ compared to their pre-traction stretched length. ${ }^{84}$ See Table 3 for a summary on the outcomes of penile straightening with penile prosthesis placement.

\section{CONCLUSION}

Surgical correction of PD with or without penile prosthesis placement remains the gold standard to correct deformity. These men need to undergo a detailed and comprehensive consent process so that the patient will be more understanding of the potential limitations of the surgery in order to set appropriate expectations thus improving postoperative satisfaction. For the man with satisfactory preoperative rigidity with curvature less than $60^{\circ}-70^{\circ}$ without significant indentation, then some form of tunica plication is indicated. There does not appear to be any one plication technique which has been demonstrated to be superior to others, as no head-to-head comparative trial has been published. In addition, for those men who have more severe, complex deformity, but who have strong preoperative erectile function and no evidence of venous insufficiency on duplex ultrasound image analysis, these men should be considered candidates for straightening with plaque incision or partial excision and grafting. The complications associated with these operations include incomplete straightening, recurrent curvature, shaft shortening, diminished penile sexual sensation and ED. Finally, for those men who have inadequate rigidity and $\mathrm{PD}$, penile prosthesis placement with straightening maneuvers as necessary should be considered first-line surgery. 
Table 3 Outcome of penile prosthesis implantation for Peyronie's disease

\begin{tabular}{|c|c|c|c|c|c|}
\hline Reference number & Prosthesis type & Number of patients & Mean follow-up duration (months) & $\begin{array}{c}\text { Additional straightening } \\
\text { maneuvers (\%) }\end{array}$ & Satisfaction rates (\%) \\
\hline \multirow[t]{2}{*}{120} & Inflatable & 129 & NA & 37 & 86 \\
\hline & Maleable & 80 & NA & 16 & 72 \\
\hline 78 & Inflatable & 90 & 49 & 96 & 84 \\
\hline 121 & Inflatable & 79 & 20 & 11 & NA \\
\hline 29 & Inflatable & 138 & NA & 8 & NA \\
\hline 82 & Inflatable & 72 & NA & 8 & 67 \\
\hline 122 & Inflatable & 46 & 12 & 61 & 93 \\
\hline 79 & Inflatable & 5 & 22 & 100 & 100 \\
\hline
\end{tabular}

Abbreviation: NA, not available.

\section{COMPETING FINANCIAL INTERESTS}

The authors declare no competing financial interests.

1 El-Sakka AI, Hassoba HM, Chui RM, Bhatnagar RS, Dahiya R et al. An animal model of Peyronie's like condition associated with an increase of transforming growth factor beta mRNA and protein expression. J Urol 1997; 158: 2284-90.

2 Rosen R, Catania J, Lue T, Althof S, Henne J et al. Impact of Peyronie's disease on sexual and psychosocial functioning: qualitative findings in patients and controls. J Sex Med 2008; 5: 1977-84.

3 Smith JF, Walsh TJ, Conti SL, Turek P, Lue T. Risk factors for emotional and relationship problems in Peyronie's disease. J Sex Med 2008; 5: 2179-84.

4 El-Sakka Al, Hassoba HM, Pillarisetty RJ, Dahiya R, Lue TF. Peyronie's disease is associated with an increase in transforming growth factor-beta protein expression. J Urol 1997; 158: 1391-4.

5 Mulhall JP, Anderson MS, Lubrano T, Shankey TV. Peyronie's disease cell culture models: phenotypic, genotypic and functional analyses. Int J Impot Res 2002; 14: 397-405.

6 Nachtsheim DA, Rearden A. Peyronie's disease is associated with an HLA class II antigen, HLA-DQ5, implying an autoimmune etiology. J Urol 1996; 156: 1330-4.

7 Schiavino D, Sasso F, Nucera E, Alcini E, Gulino G et al. Immunologic findings in Peyronie's disease: a controlled study. Urology 1997; 50: 764-8.

8 Cantini LP, Ferrini MG, Vernet D, Magee TR, Qian A et al. Profibrotic role of myostatin in Peyronie's disease. J Sex Med 2008; 5: 1607-22.

9 Ryu JK, Piao S, Shin HY, Choi MJ, Zhang LW et al. IN-1130, a novel transforming growth factor-beta type I receptor kinase (activin receptor-like kinase 5) inhibitor promotes regression of fibrotic plaque and corrects penile curvature in a rat mode of Peyronie's disease. J Sex Med 2009; 6: 1284-96

10 Larsen SM, Levine LA. Review of non-surgical treatment options for Peyronie's disease. Int J Impot Res 2012; 24: 1-10.

11 Levine LA, Greenfield JM. Establishing a standardized evaluation of the man with Peyronie's disease. Int J Impot Res. 2003; 15(Suppl 5): S103-12.

12 Bacal V, Rumohr J, Sturm R, Lipshultz LI, Schumacher M et al. Correlation of degree of penile curvature between patient estimates and objective measures among men with Peyronie's disease. J Sex Med 2009; 6: 862-5.

13 Nelson CJ, Diblasio C, Kendirci M, Hellstrom W, Guhring P et al. The chronology of depression and distress in men with Peyronie's disease. J Sex Med 2008; 5: 1985-90.

14 Wessells H, Lue T, McAninch J. Penile length in the flaccid and erect states: guidelines for penile augmentation. J Urol 1996; 156: 995-7.

15 Ohebshalom M, Mulhall J, Guhring P, Parker M. Measurement of penile curvature in Peyronie's disease patients: comparison of three methods. J Sex Med 2007; 4: 199-203.

16 Montorsi F, Guazzoni G, Bergamaschi F, Consonni P, Rigatti P et al. Vascular abnormalities in Peyronie's disease: the role of color Doppler sonography. J Urol 1994; 151: 373-5.

17 Lopez JA, Jarow JP. Penile vascular evaluation of men with Peyronie's disease. J Urol 1993; 149: 53-5.

18 Corder C, Levine LA, Rybak J. Calcified Peyronie's plauques: prevalence presentation, and treatment selection. In: Proceedings from the 16th Annual Fall Scientific Meeting of the Sexual Medicine Society of North America. 10-14 November 2010; Miami, FL, USA. Wiely: New York, USA, 2010, Poster\#41.

19 Ralph D, Gonzalez-Cadavid N, Mirone V, Perovic S, Sohn M et al. The management of Peyronie's disease: evidence-based 2010 guidelines. J Sex Med 2010; 7: 2359-74.

20 Jordan GH. Peyronie's disease. In: Wein AJ, Kavoussi LR, Novick AC, Partin AW, Peters CA editors. Campbell-Walsh Urology. Philadelphia, PA: Saunders Elsevier; 2007. p 818-38.

21 Taylor FL, Levine LA. Peyronie's disease. Urol Clin N Am 2007; 34: 517-34.

22 Taylor FL, Levine LA. Surgical correction of Peyronie's disease via tunica albuginea plication or partial plaque excision with pericardial graft: long-term follow up. J Sex Med 2008; 5: 2221-8; discussion 2229-30.

23 Levine LA, Lenting EL. A surgical algorithm for the treatment of Peyronie's disease. J Urol 1997; 158: 2149-52.

24 Ralph DJ, Minhas S. The management of Peyronie's disease. BJU Int 2004; 93: 208-15.

25 Mulhall J, Anderson M, Parker M. A surgical algorithm for men with combined Peyronie's disease and erectile dysfunction. Functional and satisfaction outcomes. J Sex Med 2005; 2: 132-8.
26 Taylor F, Abern M, Levine LA. Predicting erectile dysfunction following surgica correction of Peyronie's disease without inflatable penile prosthesis placement: vascular assessment and preoperative risk factors. J Sex Med 2012; 9: 296-301.

27 Flores S, Choi J, Alex B, Mulhall JP. Erectile dysfunction after plaque incision and grafting: short-term assessment of incidence and predictors. J Sex Med 2011; 8: 2031-7.

28 Levine LA, Dimitriou RJ. A surgical algorithm for penile prosthesis placement in men with erectile failure and Peyronie's disease. Int J Impot Res 2000; 12: 147-51.

29 Wilson SK, Delk JR 2nd. A new treatment for Peyronie's disease: modeling the penis over an inflatable penile prosthesis. J Urol 1994; 152: 1121-3.

30 Andrews HO, al-Akraa M, Pryor JP, Ralph DJ. The Nesbit operation for congenital curvature of the penis. Int J Impot Res 1999; 11: 119-22.

31 Yachia D. Modified corporoplasty for the treatment of penile curvature. J Urol 1990; 143: 80-2.

32 Gholami SS, Lue TF. Correction of penile curvature using the 16-dot plication technique: a review of 132 patients. J Urol 2002; 167: 2066-9.

33 Brant WO, Bella AJ, Lue TF. 16-dot procedure for penile curvature. J Sex Med 2007; 2 . 277-80.

34 Baskin LS, Duckett JW. Dorsal tunica albuginea plication for hypospadias curvature. J Urol 1994; 151: 1668-71.

35 Levine LA. Penile straightening with tunica albuginea plication procedure: TAP procedure. In: Levine LA, editor. Peyronie's Disease: A Guide to Clinical Management. Totowa, NJ: Humana; 2006. p151-60.

36 Greenfield JM, Lucas S, Levine LA. Factors affecting the loss of length associated with tunica albuginea plication for correction of curvature. J Urol 2006; 175: 238-41.

37 Tornehl CK, Carson CC. Surgical alternatives for treating Peyronie's disease. BJU Int 2004; 94: 774-83.

38 Alphs HH, Navai N, Kohler TS, McVary KT. Preoperative clinical and diagnostic characteristics of patients who require delayed IPP after primary Peyronie's repair. J Sex Med 2010; 7: 1262-8.

39 Levine LA, Greenfield JM, Estrada CR. Erectile dysfunction following surgical correction of Peyronie's disease and a pilot study of the use of sildenafil citrate rehabilitation for postoperative erectile dysfunction. J Sex Med 2005; 2: 241-7.

40 Dalkin BL, Carter MF. Venogenic impotence following dermal graft repair for Peyronie's disease. J Urol 1991; 146: 849-51.

41 Gelbard MK. Relaxing incisions in the correction of penile deformity due to Peyronie's disease. J Urol 1995; 154: 1457-60.

42 Levine LA, Partial plaque excision and grafting (PEG) for Peyronie's disease. J Sex Med 2011; 8: 1842-5.

43 Egydio PH, Lucon AM, Arap S. A single relaxing incision to correct different types of penile curvature: surgical technique based on geometrical principles. BJU Int 2004; 94: 1147-57.

44 Egydio PH, Lucon AM, Arap S. Treatment of Peyronie's disease by incomplete circumferential incision of the tunica albuginea and plaque with bovine pericardium graft. Urology 2002; 59: 570-4.

45 Kargi E, Yeșilli C, Hoșnuter M, Akduman B, Babuccu O et al. Relaxation incision and fascia lata grafting in the surgical correction of penile curvature in Peyronie's disease. Plast Reconstr Surg 2004; 113: 254-9.

46 Gur S, Limin M, Hellstrom WJ. Current status and new developments in Peyronie's disease: medical, minimally invasive and surgical treatment options. Expert Opin Pharmacother 2011; 12: 931-44.

47 Breyer BN, Brant WO, Garcia MM, Bella AJ, Lue TF. Complications of porcine small intestine submucosa graft for Peyronie's disease. J Urol 2007; 177: 589-91.

48 Cormio L, Zucchi A, Lorusso F, Selvaggio O, Fioretti F et al. Surgical treatment of Peyronie's disease by plaque incision and grafting with buccal mucosa. Eur Urol 2009; 55: 1469-75.

49 Simonato A, Gregori A, Varca V, Venzano F, de Rose AF et al. Penile dermal flap in patients with Peyronie's disease: long-term results. J Urol 2010; 183: 1065-8.

50 Kalsi J, Minhas S, Christopher N, Ralph D. The results of plaque incision and venous grafting (Lue procedure) to correct the penile deformity of Peyronie's disease. BJU Int 2005; 95: 1029-33

51 Usta MF, Bivalacqua TJ, Sanabria J, Koksal IT, Moparty K et al. Patient and partner satisfaction and long-term results after surgical treatment for Peyronie's disease. Urology 2003; 62: 105-9.

52 Kadioglu A, Sanli O, Akman T, Ersay A, Guven S et al. Graft materials in Peyronie's disease surgery: a comprehensive review. J Sex Med 2007; 4: 581-95.

53 Lowsley OS, Boyce WH. Further experiences with an operation for the cure of Peyronie's disease. J Urol 1950; 63: 888-902. 
54 Devine CJ Jr, Horton CE. Surgical treatment of Peyronie's disease with a dermal graft. J Urol 1974; 111: 44-9.

55 Das S. Peyronie's disease: excision and autografting with tunica vaginalis. J Urol 1980; 124: 818-9

56 Sampaio JS, Passarinho FA, Mendes CJ. Peyronie's disease. Surgical correction of 40 patients with relaxing incision and duramater graft. Eur Urol 2002; 41: 551-5.

57 Lue TF, El-Sakka Al. Venous patch graft for Peyronie's disease. Part I: Technique. J Urol 1998; 160: 2047-9.

58 Teloken C, Grazziotin T, Rhoden E, da Ros C, Fornari A et al. Penile straightening with crural graft of the corpus cavernosum. J Urol 2000; 164: 107-8.

59 Shioshvili TJ, Kakonahvili AP. The surgical treatment of Peyronie's disease: replacement of plaque by free autograft of buccal mucosa. Eur Urol 2005; 48: 129-35.

60 Brannigan RE, Kim ED, Oyasu R, McVary KT. Comparison of tunica albuginea substitutes for the treatment of Peyronie's disease. J Urol 1998; 159: 1064-8.

61 Hellstrom WJ, Reddy S. Application of pericardial graft in the surgical management of Peyronie's disease. J Urol 2000; 163: 1445-7.

62 Knoll LD. Use of small intestinal submucosa graft for the surgical management of Peyronie's disease. J Urol 2007; 178: 2474-8.

63 Chun JL, McGregor A, Krishnan R, Carson CC. A comparison of dermal and cadaveric pericardial grafts in the modified Horton-Devine procedure for Peyronie's disease. J Urol 2001; 166: 185-8.

64 John T, Bandi G, Santucci R. Porcine small intestinal submucosa is not an ideal graft material for Peyronie's disease surgery. J Urol 2006; 176: 1025-9.

65 Kovac JR, Brock GB. Surgical outcomes and patient satisfaction after dermal, pericardial, and small intestinal submucosal grafting for Peyronie's disease. J Sex Med 2007: 4: 1500-8.

66 Chung E, Clendinning E, Lessard L, Brock G. Five-year follow-up of Peyronie's graft surgery: outcomes and patient satisfaction. J Sex Med 2011; 8: 594-600.

67 Santucci RA, Barber TD. Resorbable extracellular matrix grafts in urologic reconstruction. Int Braz J Urol 2005; 31: 192-203.

68 Ma L, Yang Y, Sikka SC, Kadowitz PJ, Ignarro LJ et al. Adipose tissue-derived stem cell-seeded small intestinal submucosa for tunica albuginea grafting and reconstruction. Proc Natl Acad Sci USA 2012; 109: 2090-5.

69 da Silva FG, Filho AM, Damião R, da Silva EA. Human acellular matrix graft of tunica albuginea for penile reconstruction. J Sex Med 2011; 8: 3196-203.

70 Schultheiss D, Lorenz RR, Meister R, Westphal M, Gabouev Al et al. Functional tissue engineering of autologous tunica albuginea: a possible graft for Peyronie's disease surgery. Eur Urol 2004; 45: 781-6.

71 Imbeault A, Bernard G, Ouellet G, Bouhout S, Carrier S et al. Surgical option for the correction of Peyronie's disease: an autologous tissue-engineered endothelialized graft. J Sex Med 2011; 8: 3227-35.

72 Horton CE, Sadove RC, Devine CJ. Peyronie's disease. Ann Plast Surg 1987; 18: 122-7.

73 Moncada-Iribarren I, Jara J, Martinez-Salamanca JI, Cabello R, Hernandez C. Managing penile shortening after Peyronie's disease surgery. In: Proceedings of Annual Meeting of the American Urological Association. 19-24 May 2007; Anaheim, CA, USA. AUA: Linthicum, MD, USA, 2007, Abst 750.

74 Rybak J, Hehemann M, Corder C, Levine L. Does calcification of Peyronie's disease plaque predict progression to surgical intervention? In: Proceedings of Annual Meeting of the American Urological Association. 19-24 May 2012; San Diego, CA, USA. AUA: Linthicum, MD, USA, 2012, Poster \#1695.

75 Montorsi F, Salonia A, Briganti A. Five year follow-up of plaque incision and vein grafting for Peyronie's disease. J Urol 2004; 171: 331.

76 Montorsi F, Guazzoni G, Bergamaschi F, Rigatti P. Patient-partner satisfaction with semirigid penile prosthesis for Peyronie's disease: a 5-year follow-up study. J Urol 1993; 150: 1819-21.

77 Wilson SK, Cleves MA, Delk JR 2nd. Long-term follow-up of treatment for Peyronie's disease: modeling the penis over an inflatable penile prosthesis. J Urol 2001; 165: 825-9.

78 Levine LA, Benson JS, Hoover C. Inflatable penile prosthesis placement in men with Peyronie's disease and drug-resistant erectile dysfunction: a single-center study. J Sex Med 2010; 7: 3775-83.

79 Rahman NU, Carrion RE, Bochinski D, Lue TF. Combined penile plication surgery and insertion of penile prosthesis for severe penile curvature and erectile dysfunction. J Urol 2004; 171: 2346-9.

80 Hakim LS, Kulaksizoglu H, Hamill BK, Udelson D, Goldstein IA. Guide to safe corporotomy incisions in the presence of underlying inflatable penile cylinders: results of in vitro and in vivo studies. J Urol 1996; 155: 918-23.

81 Akin-Olugbade O, Parker M, Guhring P, Mulhall J. Determinants of patients satisfaction following penile prosthesis surgery. J Sex Med 2006; 3: 743-8.

82 Montague DK. Penile prosthesis implantation: size matters. Eur Urol 2007; 51: 887-8.

83 Wang R, Howard GE, Hoang A, Yuan JH, Lin HC et al. Prospective and long-term evaluation of erect penile length obtained with inflatable penile prosthesis to that induced by intracavernosal injection. Asian J Androl 2009; 11: 411-5.

84 Levine LA, Rybak J. Traction therapy for men with shortened penis prior to penile prosthesis implantation: a pilot study. J Sex Med 2011; 8: 2112-7

85 Leungwattanakij S, Bivalacqua TJ, Reddy S, Hellstrom WJ. Long-term follow-up on use of pericardial graft in the surgical management of Peyronie's disease. Int J Impot Res 2001; 12: 183-6.

86 El-Sakka AI, Rashwan HM, Lue TF. Venous patch graft for Peyronie's disease. Part II: Outcome analysis. J Urol 1998; 160(6 Pt 1): 2050-3.

87 Wild RM, Devine CJ Jr, Horton CE. Dermal graft repair of Peyronie's disease: survey of 50 patients. J Urol 1979; 121: 47-50.

88 Levine LA, Lenting EL. A surgical algorithm for the treatment of Peyronie's disease. J Urol 1997; 158: 2149-52.
89 O'Donnell PD. Results of surgical management of Peyronie's disease. J Urol 1992; 148: $1184-7$

90 Gelbard MK, Hayden B. Expanding contractures of the tunica albuginea due to Peyronie's disease with temporalis fascia free grafts. J Urol 1991; 145: 772-6.

91 Schwarzer JU, Muhlen B, Schukai O. Penile corporoplasty using tunica albuginea free graft from proximal corpus cavernosum: a new technique for treatment of penile curvature in Peyronie's disease. Eur Urol 2003; 44: 720-3.

92 da Ros CT, Graziottin TM, Ribeiro E, Averbeck MA. Long-term follow-up of penile curvature correction utilizing autologous albugineal crural graft. Int Braz J Urol 2012; 38: 242-7; discussion 248-9.

93 Fallon B. Cadaveric dura mater graft for correction of penile curvature in Peyronie disease. Urology 1990; 35: 127-9.

94 Staerman F, Pierrevelcin J, Ripert T, Menard J. Medium-term follow-up of plaque incision and porcine small intestinal submucosal grafting for Peyronie's disease. Int $J$ Impot Res 2010; 22: 343-8.

95 Lee EW, Shindel AW, Brandes SB. Small intestinal submucosa for patch grafting after plaque incision in the treatment of Peyronie's disease. Int Braz J Urol 2008; 34: 1916; discussion 197.

96 Adeniyi AA, Goorney SR, Pryor JP, Ralph DJ. The Lue procedure: an analysis of the outcome in Peyronie's disease. BJU Int 2002; 89: 404-8.

97 Akkus E, Ozkara H, Alici B, Demirkesen O, Akaydin A et al. Incision and venous patch graft in the surgical treatment of penile curvature in Peyronie's disease. Eur Urol 2001; 40: 531-6.

98 Montorsi F, Salonia A, Maga T, Bua L, Guazzoni G et al. Evidence based assessment of long-term results of plaque incision and vein grafting for Peyronie's disease. J Urol 2000; 163: 1704-8.

$99 \mathrm{Kim} \mathrm{DH}$, Lesser TF, Aboseif SR. Subjective patient-reported experiences after surgery for Peyronie's disease: corporeal plication versus plaque incision with vein graft. Urology 2008; 71: 698-702.

100 Kalsi JS, Christopher N, Ralph DJ, Minhas S. Plaque incision and fascia lata grafting in the surgical management of Peyronie's disease. BJU Int 2006; 98: 110-4; discussion 114-5.

101 Levine LA, Estrada CR . Human cadaveric pericardial graft for the surgical correction of Peyronie's disease. J Urol 2003; 170(6 Pt 1): 2359-62.

102 Adamakis I, Tyritzis SI, Stravodimos KG, Migdalis V, Mitropoulos D et al. A novel approach for the surgical management of Peyronie's disease using an acellular, human dermis tissue graft: preliminary results. World J Urol 2011; 29: 399-403.

103 Faerber GJ, Konnak JW. Results of combined Nesbit penile plication with plaque incision and placement of Dacron patch in patients with severe Peyronie's disease. J Urol 1993; 149(5 Pt 2): 1319-20.

104 Savoca G, Scieri F, Pietropaolo F, Garaffa G, Belgrano E. Straightening corporoplasty for Peyronie's disease: a review of 218 patients with median follow-up of 89 months. Eur Urol 2004; 46: 610-4

105 Bokarica P, Parazajder J, Mazuran B, Gilja I. Surgical treatment of Peyronie's disease based on penile length and degree of curvature. Int J Impot Res 2005; 17: 170-4.

106 Syed AH, Abbasi Z, Hargreave TB. Nesbit procedure for disabling Peyronie's curvature: a median follow-up of 84 months. Urology 2003; 1: 999-1003.

107 Ralph DJ, al-Akraa M, Pryor JP. The Nesbit operation for Peyronie's disease: 16-year experience. J Urol 1995; 154: 1362-3.

108 Licht MR, Lewis RW. Modified Nesbit procedure for the treatment of Peyronie's disease: a comparative outcome analysis. J Urol 1997; 158: 460-3.

109 Mufti GR, Aitchison M, Bramwell SP, Paterson PJ, Scott R. Corporeal plication for surgical correction of Peyronie's disease. J Urol 1990; 144: 281-2.

110 Daitch JA, Angermeier KW, Montaque DK. Modified corporoplasty for penile curvature: long-term results and patient satisfaction. J Urol 1999; 162: 2006-9.

111 Rehman J, Benet A, Minsky LS, Melman A. Results of surgical treatment for abnormal penile curvature: Peyronie's disease and congenital deviation by modified Nesbit plication (tunical shaving and plication). J Urol 1997; 157: 1288-91.

112 Chahal R, Gogoi NK, Sundaram SK, Weston PM. Corporal plication for penile curvature caused by Peyronie's disease: the patients' perspective. BJU Int 2001; 87: 352-6.

113 Geertsen UA, Brok KE, Andersen B, Nielsen HV. Peyronie's curvature treated by plication of the penile fasciae. Br J Urol 1996; 77: 733-5.

114 Thiounn N, Missirliu A, Zerbib M, Larrouy M, Dje K et al. Corporeal plication for surgical correction of penile curvature: experience with 60 patients. Eur Urol 1998; 33: 401-4.

115 van der Horst C, Martinez Portillo FJ, Seif C, Alken P, Juenemann KP. Treatment of penile curvature with Essed-Schroder tunical plication: aspects of quality of life from the patients' perspective. BJU Int 2004; 93: 105-8.

116 Schultheiss D, Meschi MR, Hagemann J, Truss MC, Stief CG et al. Congenital and acquired penile deviation treated with the Essed plication method. Eur Urol 2000; 38: 167-71.

117 Dugi D D 3rd, Morey AF. Penoscrotal plication as a uniform approach to reconstruction of penile curvature. BJU Int 2010; 105: 1440-4.

118 Paez A, Mejias J, Vallejo J, Romero I, de Castro M et al. Long-term patient satisfaction after surgical correction of penile curvature via tunical placation. Int Braz J Uro/2007; 33: 502-7; discussion 507-9.

119 Kadioglu A, Sanli O, Akman T, Cakan M, Erol B et al. Surgical treatment of Peyronie's disease: a single center experience with 145 patients. Eur Urol 2008; 53: 432-9.

120 Garaffa G, Minervini A, Christopher NA, Minhas S, Ralph DJ. The management of residual curvature after penile prosthesis implantation in men with Peyronie's disease. BJU Int 2011; 108: 1152-6.

121 DiBlasio CJ, Kurta JM, Botta S, Malcolm JB, Wan JY et al. Peyronie's disease compromises the durability and component-malfunction rates in patients implanted with an inflatable penile prosthesis. BJU Int 2010; 106: 691-4.

122 Chaudhary M, Sheikh N, Asterling S, Ahmad I, Greene D. Peyronie's disease with erectile dysfunction: penile modeling over inflatable penile prostheses. Urology 2005; 65: 760-4. 